Persp. Teol. 40 (2008) 165-179

\title{
A BUSCA DE UM ethos PLANETÁRIO
}

\section{Leonardo Boff}

Resumo: O fato de os seres humanos se sentirem na mesma casa comum, a Terra, permite-nos entender o sentido originário de ethos que em grego significa a morada humana, agora pensada globalmente. Faz-se urgente um ethos que represente um consenso mínimo que nos permite con-viver com justiça e paz. São analisadas três propostas, de Hans Küng, fundada na religião, pois é um fenômeno universal; por Enrique Dussel, baseado no pobre coletivo que compõe as grandes maiorias da humanidade e a Carta da Terra que coloca a Terra e a Humanidade no centro das preocupações, brindando valores e princípios que favorecem a solidariedade entre todos os seres humanos e a responsabilidade universal pela Terra. Por fim o autor propõe sua própria visão, fundada no cuidado e na razão sensível e cordial.

Palavras-chave: Mundialização, Ethos, Religião, Pobres, Razão sensível, Cuidado.

Aвstract: The fact of human beings feel on the same common home, the planet Earth, allows us to understand the original meaning of ethos which is in Greek human place now globally conceived. It is urgent an ethos that represents a minimum consensus letting us live together with justice and peace. It is presented three proposals, Hans Küng's based on religion for it is an universal phenomenon, Enrique Dussel's based on the collective poor who form the largest majorities of humanity, and the Earth Letter that brings Earth and humanity to the center of concerns, dealing with values and principles that support a solidarity among all human beings and the universal responsibility for the Earth. Finally the author proposes his own view, based on sensitive and cordial reason and caring.

KeY-WORDS: World approach, Ethos, Religion, Poor, Sensitive reason, Caring. 
C omo nunca antes na história do pensamento, a palavra grega ethos assume seu pleno sentido. Para os gregos, ethos significava fundamentalmente a morada humana, não em sua materialidade, mas em seu sentido existencial como aquela porção da natureza (physis) que reservamos para nós, a organizamos e cuidamos de tal modo que se transforma em nosso habitat, o lugar onde "nos sentimos em casa", protegidos e vivendo em harmonia com todos os que nela habitam, com os vizinhos e com a natureza circundante. A diligência com qual cuidamos da casa, a forma dos relacionamentos dentro dela e para fora, constroem concretamente aquilo que significa ética. Entretanto, para nós hoje, o ethos-morada não é mais a nossa casa, a nossa cidade ou o nosso país. É o inteiro planeta Terra, feito ethos-Casa Comum.

Só este fato já suscita a questão: qual deve ser o ethos que nos permite conviver todos juntos, vindos das mais diferentes regiões da Terra, com suas culturas, tradições, religiões e valores éticos? Que opções assumir, que coalizão de valores favorecer para que a comunidade/sociedade humana, a vasta comunidade de vida e a inteira comunidade terrenal possam conviver com um mínimo de paz e de justiça? ${ }^{1}$

O que se faz necessário e urgente é construir uma base comum a partir da qual podemos articular um consenso mínimo que salvaguarde e regenere a Casa Comum, hoje crucificada pela devastação ecológica e pela injustiça social internacional, e também que garanta um futuro comum Terra-Humanidade².

\section{A ética e a fase planetária da Humanidade}

Antes de abordarmos esta momentosa questão faz-se mister tomarmos consciência de que vivemos uma etapa nova da história da Humanidade e da própria Terra: a etapa planetária. Por ela fica claro que todos temos um destino e um futuro comum. E precisamos garanti-lo porque, com a situação mudada pelo aquecimento global, este está ameaçado. Precisamos, como diz a Carta da Terra, "formar uma aliança global para cuidar uns dos outros e da Terra ou arriscar a nossa própria destruição e a devastação da diversidade da vida" (Preámbulo) ${ }^{3}$.

Esse ethos a ser construído, deve tomar em conta a perspectiva básica da mundialização como no-la vem apresentada pela nova cosmologia. A Ter-

\footnotetext{
${ }^{1}$ Cf. H.CL. DE LIMA VAZ, Ética e cultura. Escritos de Filosofia II, São Paulo: Loyola, 1993; M. OLIVEIRA, Desafios éticos da globalização, São Paulo: Paulinas, 2001.

${ }^{2}$ Cf. L. BOFF, Homem: satã ou anjo bom?, Rio de Janeiro: Record, 2008.

${ }^{3}$ Carta de la Tierra. Valores y principios para un futuro sostenible, Secretaria Internacional del Proyecto Carta de la Tierra: San José (Costa Rica), 1999.
} 
ra é fruto de um longo processo de evolução que já tem 13,7 bilhões de anos. Ela como planeta existe já há 4 bilhões de anos. Nela as coisas todas não estão justapostas, mas inter-retro-conectadas. A Terra comparece como uma totalidade físico-química, biológica, sócio-antropológica e espiritual, una e complexa que articula de tal forma todas estas instâncias, formando um grande sistema vivo e benfazejo para a reprodução da vida ${ }^{4}$.

A visão que nos legaram os astronautas confirma esta compreensão. De lá da lua ou no espaço exterior, a Terra se lhes mostrava em sua esplêndida e frágil unidade. Confessavam: não há diferença entre Terra e biosfera, entre Terra e Humanidade. Elas formam uma única entidade, um todo orgânico e sistêmico.

Esta experiência de contemplar a Terra de fora da Terra está mudando o estado de consciência da Humanidade, como mudou a dos astronautas, consciência que se sente interconectada com a Terra e através da Terra com o cosmos inteiro.

A vida na Terra e da Terra aparece como emergência da complexidade de sua história, como matéria que se auto-organiza e, ao expandir-se, se autocria. A vida humana é um subcapítulo da história da vida. Aqui não há disjunção, mas conjunção. Tudo constitui um único processo complexo (portanto, não linear), dinâmico e ainda aberto para frente e para cima.

Mais ainda, com o surgimento do cibionte (a combinação do ser humano com a cibernética) entramos definitivamente numa fase nova do processo evolucionário humano 5 . Quer dizer, a tecnologia não é algo instrumental e exterior ao ser humano. Incorporou-se à sua natureza concreta. Sem o aparato técnico-científico não se pode mais entender a existência concreta e a sobrevivência humana. Pari passu está se criando um como que novo cérebro, um novo córtex cerebral, a world wide web (rede mundial de comunicação): a conexão de todos com todos, o acesso individual a todo o conhecimento e à informação acumulada pela Humanidade (via internet e a rede global de comunicação). Cada pessoa se transforma, de certa forma, num neurônio do cérebro ampliado de Gaia.

Tal fenômeno nos obriga a ir além do paradigma moderno que fraciona, atomiza e reduz. Há de se abrigar o paradigma holístico contemporâneo que articula, relaciona tudo com tudo e vê a coexistência do todo e das partes (holograma), dá a devida atenção à multidimensionalidade da realidade com sua não-linearidade, com equilíbrios/desequilíbrios, com caos/ cosmos e vida/morte. Enfim, todas as coisas devem ser contempladas na

\footnotetext{
${ }^{4}$ Cf. J. LOVELOCK, Gaia: Um novo olhar sobre a vida na Terra, Lisboa: Edições 70, 1989; ID., A vingança de Gaia, Rio de Janeiro: Editora Intrínseca, 2006.

${ }^{5}$ Cf. G. HAUSSMANN, L'uomo simbionte, Florença: Vellecchi Editore, 1992.
} 
e através de sua relação eco-organizadora com o meio-ambiente cósmico, natural, cultural, econômico, simbólico, religioso e espiritual.

Esta leitura modificou nossa concepção de mundo, do ser humano e de seu lugar no conjunto dos seres. Para nova música precisamos novos ouvidos.

Esta nova ótica demanda uma nova ética. Cabe então perguntar: que tipo de ética importa viver nesta nova fase, chamada por alguns, de era ecozóica e planetária? ${ }^{6}$

Queremos nos confrontar com três propostas de ética planetária, elaboradas a partir de distintos lugares sociais, mas que trazem elementos significativos para instituição de um possível e necessário ethos mundial. Por fim, apresentaremos a nossa própria proposta.

\section{A religião como base para um ethos mundial}

Um projeto inspirador é oferecido pelo conhecido teólogo suíço/alemão Hans Küng (nascido em 1928), que em Tübingen fundou o Instituto de Ethos Mundial.

O título de seu livro principal já anuncia sua tese de base: "Um ethos mundial para uma política mundial e para uma economia mundial"7.

Para Küng não se trata apenas de construir um ethos mínimo, mas antes de forjar um consenso mínimo acerca de um ethos universalmente válido. Este deve ser viável e efetivo e deve ser obrigatório para todas as pessoas, nas suas diferentes culturas. Como construir um consenso com tais pretensões?

Küng responde taxativamente: mediante a religião. $\mathrm{E}$ a razão reside na constatação de que a religião comparece como realidade mais universalmente difusa, base para um consenso mínimo entre os humanos. Assevera enfaticamente: "Não haverá paz entre as nações, se não existir paz entre as religiões. Não haverá paz entre as religiões, se não existir diálogo entre as religiões. Não haverá diálogo entre as religiões, se não existirem padrões éticos globais. Nosso planeta não irá sobreviver, se não houver um ethos mundial, uma ética para o mundo inteiro"s.

Esse ethos é "o mínimo necessário de valores humanos comuns, normas e atitudes fundamentais, melhor ainda, é o consenso básico com referência

${ }^{6}$ Cf. L. BOFF, Ética e espiritualidade, Campinas: Verus, 2003.

${ }^{7}$ Título original: Weltethos für Weltpolitik und Weltwirtschaft, Munique / Zurique: Piper, 1997 (em português: Uma ética global para a política e a economia mundiais, Petrópolis: Vozes, 2001); cf. também Projekt Weltethos, Munique / Zurique: Piper, 1990 (em português: Projeto de ética mundial, São Paulo: Paulinas, 1992).

${ }^{8}$ H. KÜNG, Weltethos für Weltpolitik und Weltwirtschaft, p. 131-132. 
a valores vinculantes, normas obrigatórias e atitudes básicas afirmadas por todas as religiões, apesar de suas diferenças dogmáticas e assumidas por todas as pessoas, mesmo não religiosas ${ }^{\prime \prime}$.

Küng cita em seu favor o testemunho de um dos mais significativos intérpretes do processo de globalização, Samuel P. Huntington, em seu discutido livro $O$ choque de civilizações ${ }^{10}$ : "No mundo moderno é a religião uma força central, talvez $a$ força central que motiva e mobiliza as pessoas... O que finalmente conta para elas não é a ideologia política ou o interesse econômico. Convicções religiosas e família, sangue e doutrina são as realidades com as quais as pessoas se identificam e em função das quais lutam e morrem"11.

Tal ethos, fundado na religião, possui duas pilastras de sustentação: a verdade concreta e a justiça irrenunciável, dois valores éticos elementares, compartidos por todas as religiões.

A verdade concreta, independente das teorias filosóficas sobre a verdade, fundamentalmente diz: "não queremos mais ser mentidos e ludibriados sobre nossa situação social e econômica, sobre as causas reais de nossa pobreza e exclusão social, sobre a morte prematura de nossos filhos e filhas, sobre o desaparecimento de nossos entes queridos, sobre o perigo que nos ameaça a todos".

A justiça irrenunciável, para além das formulações eruditas da academia, postula: "chega de prisões e de torturas a presos políticos, chega de privilégios no sistema financeiro nacional e mundial; chega de exploração do trabalho infantil, chega de abuso sexual a menores, chega de chacinas de meninos e meninas de rua; chega de limpeza étnica de toda uma região"! Com referência a este tipo de verdade e de justiça não cabem discussões, mas convergência mundial em valores e ações conjugadas.

Formalizando, o consenso mínimo se densifica no direito à vida, no respeito inviolável aos inocentes, no tratamento justo dispensado ao detido e na integridade física e psíquica de cada pessoa humana. É a base comum mínima, sem a qual não há convivência possível em nenhuma parte do Planeta.

É pela religião que os povos concretamente encontraram o meio para fazer valer e garantir o caráter universal e incondicional deste consenso mínimo. A religião funda a incondicionalidade e a obrigatoriedade das normas éticas muito melhor que a razão abstrata ou o discurso racional, parcamente convincentes e só compreensíveis por alguns setores da sociedade que possuem as mediações teóricas de sua apreensão. A religião, por ser

\footnotetext{
${ }^{9}$ Ibid., p. 132.

${ }^{10}$ S.P. HUNTINGTON, O choque de civilizações, Rio de Janeiro: Objetiva, 1997.

${ }^{11} \mathrm{H}$. KÜNG, Weltethos für Weltpolitik und Weltwirtschaft, p. 162.
} 
Weltanschauung mais generalizada, concretamente, o caminho comum das grandes maiorias, é mais universal e compreensível. Ela vive do Incondicional e procura testemunhá-lo como a dimensão profunda do ser humano. Só o Incondicional pode obrigar incondicionalmente.

Prescindir em qualquer análise da realidade, da dimensão religiosa, é prejudicar a análise, é encurtar a realidade, é minar o fundamento de uma atitude ética universal. Só setores racionalisticamente arrogantes da sociedade mundial desprezam esse tipo de argumentação, seja porque perderam o acesso à experiência do sagrado e do religioso, seja porque vivem alienados da vida concreta de seus próprios povos.

O cerne desta ética universal é a humanitas, a obrigatoriedade de tratar humanamente os humanos, independentemente de sua situação de classe, de religião ou de idade. As religiões históricas resumiram esse cerne na regra de ouro: "faze ao outro o que queres que te façam a ti" ou negativamente: "não faças ao outro o que não queres que te façam a ti"12.

Elas ainda ensinaram: "não matar". Traduzindo para o código moderno significa: "venere a vida; desenvolva uma cultura da não-violência e do respeito diante de toda vida". Ensinaram ainda: "não roubar". Traduzindo para os dias de hoje significa: "aja com justiça e com correção; alimente uma cultura da solidariedade e uma ordem econômica justa". Ensinaram também: "não mentir". Significa: "fale e aja com veracidade; obrigue-se a uma cultura da tolerância e a uma vida na verdade". Por fim, ensinaram: "não cometer adultério". Traduzindo: "amem-se e respeitem-se uns aos outros; imponham-se como obrigação uma cultura da igualdade e da parceria entre o homem e a mulher"13.

Uma sociedade mundial única (geosociedade) necessita de um único ethos básico; caso contrário não se garante o futuro comum; desta vez o perigo é total e a salvação deverá ser também total; não haverá uma saída escondida, salvação para alguns privilegiados; ou nos salvamos todos, mediante a incorporação de uma ética mundial, ou todos podemos conhecer o destino das grandes devastações que dizimaram outrora milhões de espécies ${ }^{14}$.

A contribuição de Hans Küng tem sido inestimável e no conjunto das propostas mundiais é uma das mais sensatas e factíveis. Entretanto, possui um limite interno. Em sua maioria, as sociedades mundiais se entendem seculares com Estados de caráter laico. Embora o que Küng afirma possa se fundar também racionalmente, encontrará dificuldades de aceitação por

\footnotetext{
${ }^{12}$ Ibid., p. 155.

${ }^{13}$ Ibid., pp. 155-156.

${ }^{14}$ Cf. M. SWEDISH, Living Beyond the "End of the World", Nova York: Orbis Books, 2008 .
} 
aqueles que não se inscrevem numa perspectiva religiosa ou que fizeram opção por outro sentido de vida, diverso do religioso.

\section{Ethos mundial a partir dos pobres}

Outra proposta nos vem de Enrique Dussel (nascido em 1934), teólogo, filósofo e historiador argentino vivendo atualmente no México ${ }^{15}$.

Ele define seu lugar social: a partir do grande Sul onde vive grande parte da Humanidade sofredora. Faz uma crítica rigorosa aos principais formuladores de um ethos mundial pelo fato de, em sua maioria, não terem consciência de seu lugar social que é o centro do poder. Deste lugar central dificilmente se dão conta de que existe uma periferia e uma exclusão mundial, fruto destes sistemas fechados, incapazes de incluir a todos e, por isso, produtores permanentes de vítimas. Como podem universalizar suas propostas se deixam de fora os pobres e os excluídos que constituem as grandes maiorias da Humanidade? Tais pensadores não fazem um juízo ético prévio do sistema histórico-social em que vivem imersos e do tipo de racionalidade que utilizam. Dão por pressuposto que suas realidades são evidentes e inquestionáveis por si mesmas.

Nesse sentido, os marginalizados e mais ainda os excluídos são portadores de um privilégio epistemológico. A partir deles, se pode fazer um juízo ético-crítico sobre todos os sistemas de poder dominantes. O excluído grita. Seu grito denuncia que o sistema social e ético está falho, é injusto e deve ser transformado.

Como universalizar um discurso ético que englobe realmente a todos sem distinção? Dussel é enfático ao afirmar que somente chegamos à universalidade se partirmos de uma parcialidade, dos últimos, dos que estão de fora, dos que têm seu ser negado. Partindo desta parte maior podemos nos abrir a todos os demais, sentindo a urgência das mudanças necessárias, capazes de garantir uma efetiva inclusão e universalidade. Deixando-os de fora, teremos discursos éticos seletivos, encobridores, não universalizáveis e abstratos.

A ética, pois, deve partir do outro, não do outro simplesmente, mas do outro mais outro que é o pobre e o excluído, o negro e o indígena, a mulher oprimida, o discriminado pelos mais variados preconceitos. Esse pobre representa mais que uma categoria econômica, constitui uma grandeza antropológica; ele tem um rosto. O rosto do pobre se desvela irredutível e provocador. Ele grita: "socorro"; estende a mão e suplica: " tenho fome,

\footnotetext{
${ }^{15}$ Cf. E. DUSSEL, Ética de la liberación en la edad de la globalización y de la exclusión, Madrid: Trotta, 1998 (em português: Ética da libertação na idade da globalização e da exclusão, Petrópolis: Vozes, 2000).
} 
dá-me de comer". Escutar a voz do outro é mostrar consciência ética. "A consciência não é tanto um aplicar os princípios ao caso concreto, mas um ouvir, um escutar a voz que interpela a partir da exterioridade, do além do horizonte do sistema: o pobre que clama por justiça a partir de seu direito absoluto, santo, de pessoa enquanto tal. Consciência ética é saber abrir-se ao outro e levá-lo a sério (responsabilidade) em favor do outro ante o sistema"16.

O princípio supremo e absoluto da ética reza: "liberta o pobre"17. O princípio é absoluto porque rege a práxis sempre, em todo o lugar e para todos. "Liberta o pobre" supõe (a) a denúncia de uma totalidade social, de um sistema fechado que exclui e produz o pobre; (b) supõe um opressor que produz o pobre e o excluído; (c) supõe o pobre injustamente feito pobre, por isso, empobrecido; (d) supõe levar em conta os mecanismos que reproduzem o empobrecimento; (e) supõe o dever ético de desmontar tais mecanismos; (f) supõe a urgência de construir um caminho de saída do sistema excludente e por fim (g) supõe a obrigatoriedade de realizar o novo sistema no qual tendencialmente todos possam caber na participação, na justiça e na solidariedade.

Essa ética arranca dos pobres, mas não é apenas para os pobres. É para todos, pois, diante do rosto do empobrecido ninguém pode ficar indiferente, todos se sentem concernidos. Essa ética é, fundamentalmente, uma ética da justiça, no sentido do resgate do reconhecimento negado às grandes maiorias e de sua inclusão na sociedade da qual se sentem excluídas. Em função disso, hierarquiza prioridades: primeiro salvar a vida dos pobres; depois, garantir os meios de vida para todos (trabalho, moradia, saúde, educação, segurança); em seguida, assegurar a sustentabilidade da casa comum, a Terra, com seus ecossistemas e a imensa biodiversidade e a partir desta plataforma básica garantir as condições para realizar os demais direitos humanos fundamentais, consignados em tantas declarações universais.

Essa ética possui um inegável caráter messiânico na medida em que leva a salvar vidas, a enxugar lágrimas, a despertar a com-paixão e a incentivar a colaboração para que todos se sintam filhos e filhas da Terra e irmãos e irmãs uns dos outros. Ela se centra em coisas essenciais ligadas à vida e aos meios da vida. Por isso tem a ver diretamente com a maioria da Humanidade empobrecida e, pelo apelo à consciência, a todos. É uma ética do óbvio humano, compreensível e realizável por todos. Suas intuições continuarão valendo enquanto não se calar o último grito do último oprimido do último rincão da Terra.

\footnotetext{
${ }^{16}$ E. DUSSEL, Ética comunitária, Petrópolis: Vozes, 1986, pp. 51-52.

${ }^{17}$ Ibid., p. 88.
} 


\section{A Carta da Terra: o ethos centrado na Terra e na Humanidade}

Uma terceira proposta de larga abrangência é apresentada pela Carta da Terra: a ética centrada na Terra e na Humanidade ${ }^{18}$. Trata-se de um documento que surgiu das bases da Humanidade, após a Eco-92 do Rio de Janeiro, envolvendo milhares de pessoas de todas as extrações sociais. Alguns representantes de todos os continentes, animados por M. Gorbachev, S. Rockfeller e Paulo Freire (após a sua morte, ocupei o seu lugar) elaboraram a Carta da Terra a partir da imensa mole dos materiais recolhidos. Disso nasceu um documento de grande beleza e elegância ética e espiritual que foi acolhido pela UNESCO em 2003 para ser inserido nos processos educativos do mundo inteiro.

A Carta da Terra representa, a meu ver, a cristalização até agora mais bem sucedida da nova consciência ecológica e planetária na perspectiva de um novo paradigma civilizatório.

Decididamente parte de uma visão ética integradora e holística, considerando as interdependências entre pobreza, degradação ambiental, injustiça social, conflitos étnicos, paz, democracia, ética e crise espiritual.

Seus formuladores dizem-no claramente: "A Carta da Terra está concebida como uma declaração de princípios éticos fundamentais e como um roteiro prático de significado duradouro, amplamente compartido por todos os povos. De forma similar à Declaração Universal dos Direitos Humanos das Nações Unidas, a Carta da Terra será utilizada como um código universal de conduta para guiar os povos e as nações na direção de um futuro sustentável"19.

O mérito principal da Carta é colocar como eixo articulador a categoria da inter-retro-conectividade de tudo com tudo. Isso lhe permite sustentar $\mathrm{o}$ destino comum da Terra e da Humanidade e reafirmar a convicção de que formamos uma grande comunidade terrenal e cósmica. As perspectivas desenvolvidas pelas ciências da Terra, pela nova cosmologia, pela física quântica, pela biologia contemporânea e os pontos mais seguros do paradigma holístico da ecologia subjazem ao texto da Carta.

Ela se divide em quatro partes, um preâmbulo, quatro princípios fundamentais e 16 princípios de apoio e uma conclusão.

O Preâmbulo afirma enfaticamente que a Terra está viva e com a Humanidade forma parte de um vasto universo em evolução. Hoje ela está

${ }^{18} \mathrm{Cf}$. L. BOFF, Ética e espiritualidade.

${ }^{19}$ Carta de la Tierra, p. 12. 
ameaçada em seu equilíbrio dinâmico devido às formas predatórias do tipo dominante de desenvolvimento que acabou por criar o aquecimento global. Face a esta situação global, temos o dever sagrado de assegurar a vitalidade, a diversidade e a beleza de nossa Casa Comum. Para isso precisamos fundar uma nova aliança com a Terra e um novo pacto social de responsabilidade entre todos os humanos, enraizado numa dimensão espiritual de reverência face ao mistério da existência, de gratidão pelo presente da vida, e de humildade face ao lugar que o ser humano ocupa na natureza como diz a Carta.

Melhor do que resumir os conteúdos éticos é dar relevo a alguns dos 16 princípios fundantes do novo ethos mundial:

- Respeitar e cuidar da comunidade de vida com compreensão, compaixão e amor;

- Proteger e restaurar a integridade dos sistemas ecológicos da Terra, com especial preocupação pela diversidade biológica e pelos processos naturais que sustentam a vida;

- Adotar padrões de produção, consumo e reprodução que protejam as capacidades regenerativas da Terra, os direitos humanos e o bem-estar comunitário;

- Erradicar a pobreza como um imperativo ético, social, econômico e ambiental;

- Afirmar a igualdade e a eqüidade de gênero como pré-requisitos para o desenvolvimento sustentável e assegurar o acesso universal à educação, ao cuidado da saúde e às oportunidades econômicas;

- Apoiar, sem discriminação, os direitos de todas as pessoas a um ambiente natural e social, capaz de assegurar a dignidade humana, a saúde corporal e o bem-estar espiritual, dando especial atenção aos povos indígenas e minorias;

- Reforçar as instituições democráticas em todos os níveis e garantirlhes transparência e credibilidade no exercício do governo, participação inclusiva na tomada de decisões e no acesso à justiça;

- Tratar todos os seres vivos com respeito e consideração;

- Promover uma cultura da tolerância, não violência e paz.

A Carta postula uma mudança na mente e no coração e requer um novo sentido de interdependência global e de responsabilidade universal. Expressa, como efeito final, a confiança na capacidade regenerativa da Terra e na responsabilidade compartida dos seres humanos de aprenderem a amar e a cuidar do Lar comum. Belamente conclui: "Que o nosso tempo seja lembrado pelo despertar de uma nova reverência face à vida, por um compromisso firme de alcançar a sustentabilidade, pela rápida luta pela justiça e pela paz, e pela alegre celebração da vida". 
Concluindo, ousamos afirmar que estamos diante de uma proposta de ética mundial, seguramente a mais articulada, universal e elegante que se produziu até agora. Se esta Carta da Terra for universalmente assumida mudará o estado de consciência da Humanidade. A Terra ganhará, finalmente, centralidade junto com todos os filhos e filhas da Terra que possuem a mesma origem e o mesmo destino que ela. Nela não haverá mais lugar para o empobrecido, o desocupado e o agressor da própria Grande Mãe. E ela, face ao novo estado de aquecimento global, encontrará seu adequado equilíbrio.

\section{A nossa proposta de uma ética do cuidado}

Todas as propostas anteriormente apresentadas possuem seu valor e contribuem poderosamente para a construção de um ethos planetário salvador.

Apresentaremos a nossa própria proposta, fundada num outro tipo de racionalidade, naquela cordial e sensível ${ }^{20}$. Constatamos que, de modo geral, quase todos os sistemas éticos, pelo menos no Ocidente, pagam pesado tributo ao logocentrismo e ao racionalismo moderno. Nos fundamentos de nossa cultura se encontra o logos grego e o cogito cartesiano. A evolução do pensamento filosófico e o próprio processo histórico vieram mostrar mais e mais que a razão não explica tudo nem abarca tudo. Antes dela vige algo de mais profundo e originário: o pathos, a afetividade e o cuidado essencial. Acima se encontra a inteligência que é a descoberta do transcendente, do eu conectado com tudo e com o Mistério que subjaz ao universo ${ }^{21}$.

Além disso existem ainda o a-racional e o irracional que mostram a presença do caos junto do cosmos, da desordem acolitando a ordem. O demens sempre acompanha o sapiens, o dia-bólico se emparelha com o sim-bólico. Há vasta convergência na admissão de que a inteligência se encontra impregnada de sensibilidade, de emoções e afetos, pois são estas características que dão conta da vida cotidiana e da sociabilidade humana. M. Meffesoli na esteira de Ortega y Gasset fala de raciovitalismo ${ }^{22}$. Podemos nos referir também à razão cordial, pois é no coração que residem os valores, o mundo das excelências, dos afetos e dos grandes sonhos que orientam a vida.

\footnotetext{
${ }^{20}$ Cf. L. BOFF, Ethos Mundial: Um consenso mínimo entre os humanos, Rio de Janeiro: Sextante, 2003; ID., Ética e Moral: A busca dos fundamentos, Petrópolis: Vozes, 2003. ${ }^{21}$ Sobre o cuidado, veja a seguinte bibliografia principal: L. BOFF, Saber cuidar: Ética do humano - compaixão pela Terra, Petrópolis: Vozes, 1999; F. TORRALBA I ROSELLÓ, Antropología del Cuidar, Barcelona: Fundación Mapfre Medicina, 1998; V.R. WALDOW, Cuidado Humano - resgate necessário, Porto Alegre: Sagra Luzzatto, 1998; S.T. FRY, A Global Agenda for Caring, New York: National League for Nursing Press, 1993, pp. 175179; ID., "The Philosophical Foundations of Caring", in M.M. LEININGER (org.), Ethical and Moral Dimensions of Care, Detroit: Wayne State University Press, 1990; M.M. LEININGER / J. WATSON, The Caring Imperative in Education, New York: Nation League for Nursing 1990; M. MAYEROFF, On Caring, New York: Harper Perennial,
} 
Qual é a experiência-base da vida humana? É o sentimento, o afeto e o cuidado. Não é o logos, mas o pathos. Sentio, ergo sum (sinto, logo existo): eis a proposição seminal. Pathos é a capacidade de sentir, de ser afetado e de afetar. Forma o Lebenswelt, o arranjo existencial concreto e protoprimário do ser humano. A existência jamais é pura existência; é uma coexistência, sentida e afetada pela ocupação e pela pre-ocupação, pelo cuidado e pela responsabilidade no mundo com os outros, pela alegria ou pela tristeza, pela esperança ou pela angústia.

A primeira relação é sem distância, de profunda passividade ativa: sentir o mundo, os outros e o eu como uma totalidade una e complexa, dentro do mundo como parte dele e, todavia, vis-à-vis a ele como distinto para vêlo, pensá-lo e moldá-lo. Fundamentalmente é um estar com e não sobre as coisas, é um con-viver dentro de uma totalidade ainda não diferenciada.

Martin Heidegger em seu Ser e Tempo ${ }^{23}$ fala do ser-no-mundo como um existencial, quer dizer, como uma experiência-base, constitutiva do ser humano e não como mero acidente geográfico ou geológico. Por isso as estruturas axiais da existência circulam em torno da afetividade, do cuidado, do eros, da paixão, da com-paixão, do desejo, da ternura, da simpatia e do amor. Esse sentimento básico não é apenas moção da psiqué, é muito mais, é uma qualidade existencial, um modo de ser essencial, a estruturação ôntica do ser humano.

O pathos não se opõe ao logos. O sentimento também é uma forma de conhecimento, mas de natureza diversa. Engloba dentro de si a razão, transbordando-a por todos os lados. Biologicamente está ligado ao cérebro límbico que irrompeu há mais de cem milhões anos e com ele surgiu, no nosso sistema planetário, o pathos, o sentimento, o cuidado e o amor. $\mathrm{O}$ pensamento racional está vinculado ao neo-córtex que emergiu apenas nos últimos 7 milhões de anos.

Quem viu genialmente esta dimensão do pathos foi Blaise Pascal, um dos fundadores do cálculo de probabilidades e construtor de máquinas de calcular, ao afirmar que os primeiros axiomas do pensamento vêm intuídos pelo coração e que cabe ao coração colocar as premissas de todo o conhecimento possível do real.

1971; J.M. MORSE et al., "Concepts of Caring and Caring as a Concept", Advances in Nursing Science 13 (1990/n ${ }^{\circ}$ 1) 1-14; N. NODDINGS, Caring: a Feminine Approach to Ethics and Moral Education, Berkeley, CA: University of California Press, 1984; P.L. CHINN, Anthology on Caring, New York: Nation League of Nursing Press, 1991; M.J. DOS S. ROSSI, "O curar e o cuidar - a história de uma relação", Revista Brasileira de Enfermagem $44\left(1991 / \mathrm{n}^{\circ}\right.$ 1) 16-21.

${ }^{22}$ Cf. M. MEFFESOLI, Elogio da razão sensível, Petrópolis: Vozes, 1998, p. 58.

${ }^{23}$ M. HEIDEGGER, Ser e Tempo, Parte I, Petrópolis: Vozes, 1989. 
A análise empírica de David Golemann com sua Inteligência emocional ${ }^{24}$ veio confirmar o que certa tradição filosófica apoiada em Platão, Agostinho, Boaventura, Pascal, chegando a Freud e Heidegger, Damásio e Meffesoli afirmava. A mente é incorporada, quer dizer, a inteligência vem saturada de emoções. É nas emoções que se elabora o universo das significações e dos sentidos existenciais. O conhecimento pelo pathos se dá num processo de sim-pathia, quer dizer, de comunhão com o real, sofrendo e se alegrando com ele e participando de seu destino.

Tal compreensão compensa o vasto racionalismo da cultura contemporânea, hegemonizada pela razão instrumental-analítica. Importa resgatar o coração, sede dos sentimentos profundos e dos valores e a razão cordial que o articula com as outras formas de exercício da razão.

Mas quem lhe deu uma fundamentação filosófica cerrada foi o já referido Martin Heidegger. Ele comenta a fábula 220 de Higino, o escravo de César Augusto, que versa sobre o cuidado ${ }^{25}$. Aí deixa claro que o cuidado é um modo-de-ser singular do homem e da mulher. Sem cuidado deixamos de ser humanos. Afirma que realidades tão fundamentais como o querer e o desejar se encontram enraizados no cuidado essencial ${ }^{26}$. Somente a partir da estrutura do cuidado elas se exercem como dimensões do humano.

O cuidado, comenta ele, é "uma constituição ontológica sempre subjacente a tudo o que o ser humano empreende, projeta e faz"; "o cuidado subministra preliminarmente o solo em que toda interpretação do ser humano se move" ${ }^{27}$. Quando diz "constituição ontológica" significa: entra na definição essencial do ser humano e determina a estrutura de sua prática. Quando fala do cuidado como "solo em que toda a interpretação do ser humano se move" significa: o cuidado é o fundamento para qualquer interpretação que dermos do ser humano. Se não tomarmos o cuidado por base não conseguiremos compreender o ser humano como um ser vivo e prático. Mais simplesmente, o cuidado (Winnicot chamaria "concern") funciona como a condição prévia para que qualquer ser venha à realidade e representa o norteador antecipado dos comportamentos humanos. Se não tivesse imperado o cuidado, como nos primeiríssimos momentos após o big bang, e as energias originárias com a matéria primordial não tivessem mantido um sutilíssimo equilíbrio, não haveria condições para que surgisse a matéria, daí as estrelas e a vida, e nós não estaríamos aqui para falar disso tudo. Portanto, o cuidado é a condição prévia para a emergência dos seres. Se não alimentarmos o cuidado, a ação se torna atabalhoada quando não irresponsável.

${ }^{24}$ Cf. D. GOLEMANN, A inteligência emocional, Rio de Janeiro: Objetiva, 1995.

${ }^{25}$ Cf. M. HEIDEGGER, Ser e Tempo, Parte I, §§ 41-43.

${ }^{26}$ Cf. ibid., § 41, p. 258.

${ }^{27}$ Ibid., § 42, p. 265. 
O cuidado, portanto, funda um novo ethos, no sentido originário do ethos grego como referimos anteriormente: a forma como organizamos nossa casa, o mundo que habitamos com os seres humanos e com a natureza.

O ser humano é fundamentalmente um ser de cuidado e sensibilidade mais que um ser de razão e de vontade. Cuidado é uma relação amorosa para com a realidade com o objetivo de garantir-lhe a subsistência e criar-lhe espaço para o seu desenvolvimento, como o temos desenvolvido em nossa investigação Saber cuidar: ética do humano - compaixão pela Terra ${ }^{28}$. O cuidado previne os danos futuros e regenera os danos passados. Correspondente ao cuidado, em termos do discurso ecológico, é a sustentabilidade que visa encontrar o justo equilíbrio entre a utilização racional das virtualidades da Terra e sua preservação para nós e para as gerações futuras.

Em tudo os humanos colocam e devem colocar cuidado: com a vida, com o corpo, com o espírito, com a natureza, com a saúde, com a pessoa amada, com quem sofre e com a casa. Sem cuidado a vida perece.

A ética do cuidado é seguramente a mais imperativa nos dias atuais, dado o nível de descuido e desleixo que paira como uma ameaça sobre a biosfera e o destino humano, objeto de crescentes alarmes dos grandes organismos ecológicos mundiais.

A partir desta plataforma globalizante do pathos enriquecido pela tradição do $\log o s$, tendo no cuidado essencial sua expressão maior, derivam-se outras dimensões éticas, estreitamente ligadas ao cuidado. Aqui apenas as referimos, pois as temos desenvolvido mais detalhadamente alhures ${ }^{29}$ : a ética da com-paixão para com todos os seres que sofrem, a começar pelo planeta como um todo, as espécies em extinção e especialmente os seres humanos submetidos aos bilhões a grandes tribulações. Junto à compaixão comparecem a solidariedade/cooperação, atitudes radicais mais que virtudes, pois foi por elas que o ser humano deu o salto da animalidade para a humanidade e ainda hoje estão na base de qualquer forma de sociabilidade. Por fim, ao cuidado pertence a responsabilidade. Por ela nos damos conta das conseqüências de nossos atos, se benfazejos ou funestos. Importa cuidar para que, com consciência e plena atenção, nossas práticas não sacrifiquem o sistema da vida e agravem o estado da Terra e da humanidade.

Duas virtudes acompanham a ética do cuidado: a autolimitação e a justa medida. A autolimitação é a renúncia necessária que fazemos de nossos desejos e da voracidade produtivista e consumista para salvaguardar a

\footnotetext{
${ }^{28}$ L. BOFF, Saber cuidar: Ética do humano - compaixão pela Terra, Petrópolis: Vozes, 1999.

${ }^{29}$ Cf. L. BOFF, Ethos Mundial: Um consenso mínimo entre os humanos, Rio de Janeiro: Sextante, 2003.
} 
integridade e a sustentabilidade do nosso planeta. A autolimitação tutela os interesses privados para que não se sobreponham aos coletivos que formam o bem comum. Inspira uma cultura da simplicidade voluntária e um consumo responsável e solidário.

A justa medida é o apanágio de todas as grandes tradições éticas e espirituais do Ocidente e do Oriente. Ela está na base de todas as virtudes, porque a justa medida é o ótimo relativo, o equilíbrio entre o mais e o menos. Nossa cultura é em tudo excessiva e peca pela hybris (auto-estima demasiada e arrogância) tão condenada pela cultura grega.

Hoje se coloca continuamente a seguinte questão: qual é a justa medida de nossa intervenção na natureza para satisfazer nossas necessidades e, ao mesmo tempo, conservar o capital natural de modo que ele possa se regenerar e ser passado de forma enriquecida às gerações futuras.

Estimo que o futuro da vida e da Humanidade depende de nossa autolimitação, de nossa justa medida e do cuidado que nutrirmos permanentemente para que o dom mais precioso que a natureza nos legou e que Deus fez suscitar no longo processo de evolução - a vida - possa se manter e continuar a co-evoluir na escalada rumo ao seu ponto Ômega.

Leonardo Boff, 1938, doutorou-se em Munique em teologia sistemática em 1970. Foi por 22 anos professor de teologia no Instituto Franciscano de Petrópolis e posteriormente professor de ética e filosofia da religião na Universidade do Estado do Rio de Janeiro. Foi professor visitante em Lisboa, Salamanca, Harvard, Basel e Heidelberg. É portador de três títulos de doutor honoris causa por Lund (Suécia), Turim (Itália) e São Leopoldo (Brasil), além de professor de honra pela Universidade de Guatemala e da Universidade de Cuenca (Ecuador). Membro da Iniciativa da Carta da Terra e um de seus redatores, autor de mais de 70 livros nas áreas da teologia, filosofia, ética e ecologia.

Endereço: Caixa Postal 92144 - Itaipava

25741-970 Petrópolis - RJ

www.leonardoboff.com

e-mail: lboff@leonardoboff.com 


\section{COLEÇÃO THEOLOGICA}

A coleção THEOLOGICA, sob responsabilidade da Faculdade Jesuíta de Filofosofia e Teologia, divulga obras científicas no campo da teologia, produzidas por especialistas de renome, brasileiros ou estrangeiros, e destinadas em primeiro lugar às Faculdades e Institutos de Teologia e/ou Ciências da Religião, bem como aos pastores e estudiosos de teologia em geral. Tornando acessível os novos estudos, procura incentivar a pesquisa e discussão em nível científico.

\section{TÍTULOS PUBLICADOS:}

1. Eu creio, nós cremos. Tratado da fé (J. B. Libanio)

2. As lógicas da cidade (J. B. Libanio)

3. Inculturação da fé. Uma abordagem teológica (Mario de França Miranda)

4. Nas fontes da vida cristã. Uma teologia do batismo-crisma (Francisco Taborda)

5. Crer no amor universal. Visão histórica, social e ecumênica do "Creio em Deus Pai" (Carlos Josaphat)

6. Igreja, povo santo e pecador (Álvaro Barreiro)

7. Jesus e a Política da Interpretação (Elisabeth Schüssler Fiorenza)

8. A religião no início do milênio (J. B. Libanio)

9. Olhando para o futuro (J. B. Libanio)

10. "Num só corpo". Tratado mistagógico sobre a eucaristia (Cesare Giraudo)

11. O Cristianismo e as religiões. Do desencontro ao encontro (Jacques Dupuis)

12. A salvação de Jesus Cristo. A doutrina da graça (Mario de França Miranda)

13. Karl Rahner em perspectiva (Pedro Rubens / Claudio Paul)

14. Concilio Vaticano II. Em busca de uma primeira compreensão (J.B. Libanio)

15. Karl Rahner - 100 anos. Teologia, filosofia e experiência espiritual (Pedro Rubens / Francisco Taborda)

16. A Igreja numa sociedade fragmentada. Escritos Eclesiológicos (Mario de França Miranda)

17. Do viver apático ao viver simpático. Sofrimento e morte (Edson Fernando de Almeida)

18. Os carismas na Igreja do terceiro milênio: Discernimento, desafios e práxis (J. B. Libanio)

19. O Deus im-potente. O sofrimento e o mal em confronto com a cruz (Paulo Roberto Gomes)

20. Sabedoria da paz. Ética e teo-lógica em Emmanuel Levinas (Nilo Ribeiro Junior)

21. Pastoral nas megacidades (Brigitte Saviano)

Edições Loyola - Cx. P. 42.355 - CEP 04299-970 São Paulo

e-mail: vendas@loyola.com.br 